\title{
Ventricular Arrhythmia Burden in Patients with Heart Failure and Cardiac Resynchronisation Devices - The Importance of Renal Function
}

G G Babu, M Webber, R Providencia, Kumar S, A B Gopalamurugan, DP Rogers, Daw H, S Ahsan, F Z Khan, A W Chow, M D Lowe, E Rowland, Lambiase P D, O R Segal

Corresponding Author

Dr Oliver R Segal

Consultant Cardiologist

Barts Heart Centre 


\begin{abstract}
Words: 246

BACKGROUND: Chronic kidney disease (CKD) is a risk factor for arrhythmias in patients with heart failure (HF). However, the effects of CKD on ventricular arrhythmia burden in patients with cardiac resynchronisation therapy and defibrillator (CRT-D) devices in a primary prevention setting are unknown.
\end{abstract}

OBJECTIVE: To determine whether baseline CKD is associated with increased risk of ventricular arrhythmia (VA) in patients implanted with primary prevention CRT-D devices.

METHODS and RESULTS: In this retrospective study, 199 consecutive primary prevention CRT-D recipients (2005-2010) were stratified by estimated glomerular filtration rate (eGFR) levels prior to device implantation with 106 (53.2\%) $\geq$ CKD III (eGFR <60ml/min/1.73m²) (CKD group). CKD group patients were significantly older $(70.0 \pm 10 y$ vs. $61.3 \pm 12 y, p<0.05)$ with higher prevalence of ischemic cardiomyopathy $(56.2 \%$ vs. $40.2 \%, p<0.05)$. Detected ventricular tachycardia $(\mathrm{VT}) /$ ventricular fibrillation (VF) episodes resulting in device therapy occurred significantly more frequently in the CKD group [40/106(37.8\%)] than controls [24/93(25.8\%)], (OR=1.74, 95\% $\mathrm{Cl}=1.01-3.2, \mathrm{p}=0.05)$. At 5year follow up, interval censored data analysis showed 41\% VT/VF incidence in the CKD group compared to $24 \%$ incidence in controls, $(p<0.05)$. Cox proportional hazards model identified CKD >III as the only predictor of sustained VA in this group (adjusted HR 2.92, $\mathrm{Cl}=1.39-6.1, \mathrm{p}=0.004$ ).

CONCLUSION: Baseline CKD is a strong independent risk factor for ventricular arrhythmia in primary prevention CRT-D recipients. Further understanding of the underlying arrhythmogenic mechanisms relating to CKD may be of interest to allow appropriate correction and prevention. Device programming in this cohort may need to reflect this increased risk.

Key-words: Cardiac resynchronisation therapy, Chronic Kidney Disease, Implantable cardioverter defibrillator, Heart failure, Renal failure. 
Abbreviations:

ATP - Anti-tachycardia Pacing

CAD - Coronary artery disease

CKD - Chronic Kidney Disease

CRT-D - Cardiac Resynchronisation Therapy- Defibrillator

EF - ejection fraction

eGFR - Estimated Glomerular Filtration rate

EGM - electrogram

HF - Heart Failure

ICD - Implantable Cardioverter Defibrillator

LV - left ventricle

MI - Myocardial infarction

MDRD - Modified Diet in Renal Disease

NKF KDOQI - The National Kidney Foundation Kidney Disease Outcomes Quality Initiative NYHA - New York Heart Association

SCD - Sudden Cardiac Death

VA - Ventricular Arrhythmia

VT - Ventricular tachycardia

VF - Ventricular Fibrillation 


\section{Introduction}

Cardiac Resynchronisation Therapy (CRT) is an established adjunctive therapy in treating patients with heart failure (HF) with proven mortality benefit. ${ }^{1}$ It is well recognised that patients with $\mathrm{HF}$ and poor left ventricular function are at increased risk of sudden cardiac death (SCD) due to ventricular arrhythmia (VA). ${ }^{2}$ Therefore, many patients suitable for CRT are also candidates for primary prevention defibrillator therapy. ${ }^{3}$ However, these devices are also associated with possible complications ${ }^{4}$ and some patients may not benefit from implantable cardioverter defibrillators (ICDs) as they do not experience a ventricular tachycardia (VT)/ventricular fibrillation (VF) episode in their lifetime..$^{5-7}$ Identifying individuals most likely to benefit from ICDs remains unresolved. ${ }^{5}$

Chronic Kidney Disease (CKD) is common in congestive HF (CHF) patients. Up to $40 \%$ of patients with CHF have been reported to have CKD with estimated glomerular filtration rate (eGFR) $<60 \mathrm{mls} / \mathrm{min} / 1.73 \mathrm{~m}^{2}$, as found in the ANCHOR (Anaemia in chronic heart failure: Outcomes and Resource Utilization) registry. ${ }^{8}$ CKD is a powerful independent predictor of fatal and non-fatal adverse cardiovascular outcomes in patients post-myocardial infarction (MI), as well as in patients with $\mathrm{CHF}$, with both preserved or reduced left ventricular ejection fraction (LVEF). ${ }^{9-12} \mathrm{~A}$ recent metaanalysis found an incremental $7 \%$ 1-year mortality rate for every $10 \mathrm{ml} / \mathrm{min}$ decrease in eGFR in patients with renal impairment and HF. ${ }^{13}$

Cardiac resynchronisation therapy (CRT), through its long term reverse remodelling effects on the left ventricle, is known to decrease the incidence of sudden cardiac death (SCD) due to ventricular arrhythmia in CHF patients. ${ }^{1 ; 3}$ Therefore, pathological processes negatively impacting reverse remodelling are likely to diminish the protective effect of CRT on SCD. A sub-group analysis of "resynchronization reverses remodelling in Systolic Left ventricular dysfunction" (REVERSE) study showed CKD patients with CRT had significantly less improvement in reverse remodelling parameters compared to those with normal renal function. ${ }^{14}$ We hypothesise that the incidence of sustained ventricular arrhythmia among CHF patients receiving CRT therapy is likely to be higher in patients 
with renal impairment. Retrospective analysis of device data in patients receiving CRT-D therapy in the primary prevention setting was performed to determine whether baseline renal impairment has an independent effect on ventricular arrhythmic burden.

\section{Methods}

Consecutive patients receiving CRT-D therapy from January 2005 to December 2010 at our centre were identified through computerised databases. A total of 442 patients underwent CRT-D implantation during this period. Of these, 160 (36.2\%) underwent CRT-D implantation for secondary prevention purposes and were excluded. Patients receiving CRT-D devices in the context of hypertrophic cardiomyopathy and congenital heart disease were excluded from further analysis to avoid confounding results due to the different ventricular arrhythmia burden and substrates in these special groups. Patients with LVEF $>35 \%$ on transthoracic echocardiography prior to CRT-D device implantation were also excluded from further analysis, as were patients in whom LV lead insertion was unsuccessful to preserve homogeneity in comparative groups. The remaining $199 \mathrm{CHF}$ patients who underwent CRT-D for primary prevention comprised the study population (Figure 1). Data were extracted with respect to baseline patient demographics, LVEF, New York Heart Association (NYHA) class, anti-arrhythmic medications, baseline serum creatinine and eGFR at the time of device implantation.

The study cohort was categorised into 2 groups based on baseline eGFR: CKD group (patients with eGFR $\leq 60 \mathrm{ml} / \mathrm{min} / 1.73 \mathrm{~m}^{2}$ ) and the Control group (patients with eGFR $>60 \mathrm{ml} / \mathrm{min} / 1.73 \mathrm{~m}^{2}$ ). The eGFR was calculated using the Modified Diet in Renal Disease (MDRD) formula: eGFR $\left(\mathrm{mL} / \mathrm{min} / \mathbf{1 . 7 3 \mathrm { m } ^ { 2 } )}\right.$ = $175 \times$ [serum creatinine $(\mu \mathrm{mol} / \mathrm{L}) \times 0.0113]^{-1.154} \times$ age $(\text { years })^{-0.203}(\times 0.742 \text { if female })^{15}$

In patients identified to have eGFR $<60 \mathrm{ml} / \mathrm{min} / 1.73 \mathrm{~m}^{2}$, past eGFR measurements over 6 months were ascertained, to determine that low eGFR was indeed a true reflection of CKD and not acute 
renal impairment. An eGFR $<60 \mathrm{ml} / \mathrm{min} / 1.73 \mathrm{~m}^{2}$ denotes the presence of at-least moderate renal impairment, and defined as CKD stage 3, according to The National Kidney Foundation Kidney Disease Outcomes Quality Initiative (NKF KDOQI) guidelines. In addition, population based studies have shown that CKD stage 3 is associated with twice the risk of sudden cardiac death (SCD) in patients with renal impairment. ${ }^{16}$ Therefore eGFR $<60 \mathrm{ml} / \mathrm{min}$ was selected as the cut-off to define CKD stage 3 in the present study. To corroborate this, we also assessed the optimal cut-off for eGFR in our sample using a ROC curve to obtain the Youden index (best combination of specificity and sensitivity) in determining the ventricular arrhythmic burden.

Data from device clinic follow-up records and stored device electrograms (EGMs) during episodes of detected VT/VF and therapy deliveries were retrospectively analysed for at least 5 years in all surviving patients. Therapy delivery was defined as either anti-tachycardia pacing (ATP) or appropriate ICD shocks for ventricular arrhythmia. Detected ventricular arrhythmia episodes were classified as either 1) Non-sustained VT (NSVT) - defined as ventricular tachycardia meeting detection criteria that terminated spontaneously without therapy delivery or 2) VT/VF defined as ventricular sustained tachyarrhythmia meeting detection criteria that resulted in therapy delivery. VT episodes which met detection criteria but terminated before re-confirmation were classified as NSVT. Therapies delivered due to inappropriate tachycardia detections (for supra-ventricular tachycardia, sinus tachycardia, sensing failure or artefact and determined by analysis of stored EGMs for each episode) were not included for analysis. Although data regarding multiple shocks/therapies in a single patient were collected and incidences compared, for the purpose of time to event analysis, only time to first event was considered (Kaplan-Meier analysis and Cox Regression). Patients were censored after the first sustained ventricular arrhythmia needing therapy. Mortality data (all cause mortality) were collected through computerised databases, hospital records and by collecting data through patients' registered general practitioners in those lost to hospital/device clinic follow-up. 
Tachycardia detection criteria were altered in some patients during the analysis period to allow optimal arrhythmia management following VA episodes, and for patients with lead advisories or those in whom artefact had been recorded on the right ventricular pace-sense component, or patients with frequent but more prolonged episodes of NSVT leading to ATP. Permission to retrospectively review medical records for this analysis was obtained from the local ethics committee.

\section{Statistical analysis}

Categorical variables in each group are presented as percentages and continuous variables as mean $( \pm S D)$ and/or median (interquartile range) where appropriate. Categorical variables were compared by the $X^{2}$ test. Continuous variables were compared by Student's t-test. Kaplan-Meier analysis was performed to estimate freedom from VT/VF and the log rank test was used for time to event comparison. Cox proportional hazards (Forward stepwise conditional method; probability for stepwise $=0.05)$ was used to evaluate the effects of co-variates in the time to event analysis. A pvalue $<0.05$ was considered statistically significant. Statistical analysis was performed using the statistical software SPSS version 15 (SPSS Inc., Chicago, IL, USA).

There are no previous studies assessing the incidence of VT/VF in a cohort of CKD patients with CRTD and, therefore, an exploratory study with no previous power assessment to document an association between CKD and VT/VF in this population was performed.

\section{Results}

\section{Baseline characteristics}

A total of 199 patients underwent CRT-D device implantation for primary prevention between January 2005 and December 2010 (Figure 1). Mean age was 66.05 \pm 12.1 years and 54 (27.1\%) were female. 106 patients $(53.3 \%)$ had an eGFR $<60 \mathrm{mls} / \mathrm{min} / 1.73 \mathrm{~m} 2$ (CKD group) immediately prior to the implant and the remaining 93 patients (46.7\%) constituted the control group. 
Baseline characteristics in the two groups are shown in Table 1. Both groups were similar with respect to sex distribution, baseline LVEF, baseline QRS duration and use of medications - including ACE inhibitors, beta-blockers and amiodarone at the time of device implantation. CKD group patients were older $(70.06 \pm 10$ yrs vs. $61.3 \pm 12$ yrs $p<0.01)$, had a higher proportion of ischemic cardiomyopathy- $(56.2 \%$ vs. $40.2 \% \mathrm{p}<0.05)$ and a higher prevalence of $\mathrm{AF}$ at the time of implantation (36.7\% vs. $18.3 \%, p<0.05)$.

\section{Device programming}

The distribution of device manufacturers were Boston Scientific (60\%), Medtronic (21\%), St Jude (17\%) and Biotronik (1\%). Although all devices were for primary prevention purposes, most were programmed with two therapy zones, reflecting practice during the time period of 2005-2010. In general, a VT zone for ventricular rates $>171 \mathrm{bpm}$ with detection requiring approximately $2.5-9.0 \mathrm{~s}$ (depending on manufacturer) and a VF zone for ventricular rates $>210 \mathrm{bpm}$, with detection requiring approximately 1.0s-5.0s (depending on manufacturer) summarises device programming in the study cohort. There was no difference in the biventricular pacing percentage between the two groups (94.4\% vs $96.1 \%$ (CKD vs control) group, $p=0.84$ )

\section{Incidence of Ventricular Tachyarrhythmia}

Mean follow up duration was longer in the control group ( $55.5 \pm 30$ vs. $44.2 \pm 28$ months, $p=0.007)$. The exact incidence and interval censored incidence of ventricular arrhythmia were calculated. VT/VF requiring device therapy occurred significantly more frequently in the CKD group 40/106(37.8\%) than controls 24/93(25.8\%), (OR=1.74, 95\% $\mathrm{Cl}=1.01-3.2, \mathrm{p}=0.05)$. At 5-year follow up, an interval censored data analysis showed $41 \%$ VT/VF incidence in the CKD group compared to $24 \%$ incidence in controls (Figure 2, $\mathrm{p}<0.05$ ). ROC Curve analysis for VT/VF occurrence and eGFR values, identified an e-GFR of $59.5 \mathrm{ml} / \mathrm{min}$ as the optimal cut-off point (Youden index). 
Incidence of recurrent VTs ( $\geq 2$ VT/VF episodes requiring therapy) was observed in 15/106 (14.2\%) patients in the CKD group and 10/93 (10.8\%) in the control group, but did not achieve statistical significance (OR=1.19, $\mathrm{Cl}=0.79-1.97, \mathrm{p}=0.52)$.

Inappropriate therapies occurred in $6.1 \%$ of patients (12). There was no difference in the incidence of inappropriate therapy in the two groups, CKD group $5.7 \%$ vs $6.5 \%$ in the control group, $p=0.96$.

Kaplan-Meier survival curves (Figure 3) showed a higher incidence of first sustained VT/VF over time in CKD patients $(p=0.003, H R=2.034,95 \% \mathrm{Cl} 1.22-3.39)$. By 5 years follow-up $41 \%$ of patients in the CKD group experienced appropriate ICD interventions for sustained VA (Figure 3), compared with only $24 \%$ in the control group. Based on these figures, the calculated number needed to treat (NNT) for CKD patients undergoing ICD implantation to receive an appropriate ICD therapy is 5.9.

\section{Predictors of VT/VF}

On univariate Cox regression, male sex $(H R=1.9095 \% C l=1.02-3.5, p=0.04)$, baseline LVEF $(H R=0.96$, 95\% $\mathrm{Cl}=0.93-1.0, \quad \mathrm{p}=0.051)$ and $\mathrm{CKD}$ stage $>\mathrm{III} \quad(\mathrm{HR}=2.034,95 \% \mathrm{Cl}=1.22-3.39, \mathrm{p}=0.007)$ were independent predictors of a first VT/VF event. However, multivariate Cox regression identified CKD stage $>$ III as the only independent predictor of sustained VA occurrence in this cohort $(H R=2.05$, 95\% $\mathrm{Cl}=1.14-3.68, \mathrm{p}=0.016)$. Age, gender, baseline LVEF, etiology of HF (ischemic vs. non-ischemic), use of ACE-inhibitors, beta-blockers and amiodarone were not found to be independent risk factors using this multivariate model.

\section{Mortality data}

During the follow-up period, 82 deaths were recorded, implying an overall $41.2 \%$ mortality in this cohort. The mortality rate was significantly higher in the CKD group compared to the control group, $47.2 \%$ vs $34.4 \%$, OR $1.336,95 \% \mathrm{Cl}=0.97-1.84, \mathrm{p}=0.06$ ). Kaplan-Meier survival curves (Figure 4) showed significant differences in mortality, with increased overall mortality in the CKD group, log rank $5.15, p=0.023$. Survival rates at 1,2 , and 5 years in two groups were $93 \%, 90 \%$ and $68 \%$ in 
control group and were $94 \%, 86 \%$ and $57 \%$ in CKD group. However, a Cox proportional hazards model did not identify CKD as an independent predictor for mortality. None of the covariates showed significance in Cox proportional hazard modelling for mortality, with male sex closest to significance (Table 3).

\section{Discussion}

Results from the present study demonstrate that baseline renal impairment is an independent predictor of sustained ventricular arrhythmia necessitating ICD therapies in patients with CRT-D devices implanted for primary prevention.

CKD is an established independent risk factor for all cause mortality, even in non-dialysis dependent patients, ${ }^{17}$ and the incidence of cardiovascular disease is very common in this cohort, which has also been found to be the commonest mode of death in population based studies. ${ }^{18-20}$ Significant proportions of patients with CKD suffer sudden cardiac death, unrelated to atherosclerotic events or heart failure, suggesting different pathophysiologies play a role. ${ }^{21}$ The finding of increased incidence of malignant ventricular arrhythmias in HF patients with CKD in patients with CRT devices in the present study may imply greater vulnerability to arrhythmia in the general heart failure population with concomitant CKD and merits further study. In a recent retrospective study of patients undergoing primary prevention ICD implantation, it was shown that CKD was an independent predictor of appropriate ICD therapies. ${ }^{22}$

Despite ICD implantation, CKD patients have significantly poorer prognosis due to multiple factors, including worsening $\mathrm{HF}$ due to $\mathrm{CKD}$, progression of coronary artery disease (CAD) due to hypercalcaemia and increased inflammation, advanced age at presentation and the effects of chronic anaemia. ${ }^{23-25}$ In the Multicenter Automatic Defibrillator Implantation Trial II (MADIT II) study, which examined ICD placement versus medical therapy in CHF patients, serum creatinine was found 
to be an independent predictor of time to first appropriate ICD shock or therapy. ${ }^{26}$ In a post-hoc subgroup analysis of MADIT II trial each $10 \mathrm{ml} / \mathrm{min} / 1.73 \mathrm{~m} 2$ reduction in eGFR increased the risk of all-cause mortality and SCD by $16 \%(p=0.005)$ and $17 \%(p=0.03)$, respectively. ${ }^{27}$ However, those patients with more advanced renal failure have a greater propensity for non-arrhythmic modes of death, implying a dynamic arrhythmic substrate with disease progression. ${ }^{28}$ These findings have, as a consequence, led to the development of decision models for implantation of primary prevention ICDs in CKD patients. ${ }^{29}$

In contrast to the studies involving CKD patients undergoing ICD implantation, the outcomes of CKD patients undergoing CRT implantation has not shown compelling evidence of poor prognosis when compared to patients with normal renal function. Sub-group analyses of CARE-HF, RAFT and REVERSE studies showed no difference in the primary outcomes in patients with CKD compared to patients without. ${ }^{30-32}$ However, a sub-group analysis of the COMPANION trial showed a significant increase in SCD in patients with CKD (HR: $1.69 ; 95 \% \mathrm{Cl}: 1.06$ to $2.69 ; \mathrm{p}=0.03$ ). ${ }^{33}$ None of these randomised studies were sufficiently powered to assess the impact of renal function and outcomes and, consequently, no clear recommendations are available for CKD patients regarding benefit of CRT, nor decision models developed. Results from the present study suggest that in HF patients with CRT-D devices implanted for primary prevention, a higher arrhythmic burden is found in CKD patients.

\section{Putative role of renal dysfunction in risk of ventricular arrhythmia}

Structural and electrophysiological remodelling of the heart, vascular calcification and fibrosis, autonomic dysregulation, and volume and electrolyte shifts are some of the underlying processes thought to explain the increased predisposition for SCD in people with CKD. ${ }^{25}$

A sustained ventricular arrhythmia requires interplay between two important factors. Firstly, a transient event (or a trigger) and secondly an underlying myocardial substrate which poses an 
electrical instability for ventricular arrhythmia to be sustained. ${ }^{25}$ Adverse cardiac remodeling that includes left ventricular hypertrophy and fibrosis in CKD patients is described in many studies and this is possibly the most important mechanism through which the myocardial substrate becomes vulnerable to VA. ${ }^{34-38}$ Commonly associated co-morbidities in CKD patients, i.e diabetes mellitus, hypertension and anaemia partly contribute to adverse left ventricular remodeling. ${ }^{39 ; 40}$ The molecular basis for these changes includes activation of growth factors, proto-oncogenes, plasma noradrenalin, cytokines, and angiotensin II. These factors regulate intracellular processes that accelerate cardiac hypertrophy, myocardial fibrosis, and apoptosis. ${ }^{25 ; 41 ; 42}$ Both left ventricular hypertrophy and cardiac fibrosis have been implicated in increasing the risk for sustained ventricular arrhythmias and the predisposition to $\mathrm{SCD} \cdot{ }^{38 ; 43}$ Structural changes can alter the electrophysiological properties of the myocardium. Fibrosis disrupts the normal myocardial architecture and results in a slowing of conduction velocity across the diseased tissue. ${ }^{25}$ This pathology can form heterogeneous zones of conduction and repolarization that can sustain a re-entrant arrhythmia such as ventricular tachycardia. ${ }^{44-46}$ Cardiac fibrosis and left ventricular hypertrophy have been implicated in various studies to cause early after depolarisations, which acts as a trigger in inducing ventricular arrhythmias. ${ }^{47 ; 48}$ Sympathetic hyperactivity is a well established phenomenon occurring in patients with renal impairment. ${ }^{49 ; 50} \mathrm{~A}$ decreased beta blockade effect in patients with renal impairment has been demonstrated and certainly could contribute to increased the ventricular arrhythmia observed when compared to patients without renal dysfunction. ${ }^{51}$ Plasma norephinephrine levels in CKD patients is also linked with higher incidence of all cause cardiovascular mortality. ${ }^{52}$ Various electrolyte abnormalities observed in renal dysfunction, including hyperkalemia, uremia, and metabolic acidosis contribute to a pro-arrhythmic state in these patients, however, this is more often observed in end stage CKD patients dependent on hemo-dialysis. ${ }^{24}$ In patients with advanced renal disease needing hemo-dialysis, ventricular repolarization heterogeneity manifested by increased QT dispersion is another reason to develop malignant arrhythmias. ${ }^{53}$ 
In the current study, patients with severe CKD (e-GFR $<30)$ were only a minority $(n=3)$. Two of these 3 patients (66\%) developed sustained VT/VF during follow up compared to $20.5 \%$ of patients with eGFR $>30$. However, owing to the very small number of these patients in our study, statistical significance was not reached.

\section{Conclusions}

Baseline CKD is a strong independent predictor for ventricular arrhythmia in primary prevention CRT-D recipients in this retrospective, single-centre analysis. Further understanding of the underlying arrhythmogenic mechanisms in CKD may be of interest to allow a better treatment and prevention approach of dysrhythmia in this subset of patients. $>50 \%$ of patients with primary prevention CRT-D devices have CKD and CKD is an independent risk factor for developing ventricular arrhythmia resulting in device therapy in this study. The presence of CKD, however, does not influence mortality. Results suggest the presence of CKD should be incorporated into decision models for identifying patients with LV dysfunction likely to benefit from device therapy and used to identify those at greater risk of receiving ICD therapies after implant.

\section{Limitations}

There are several limitations to this study. The study cohort was small and retrospectively analysed and based on data from only a single centre. Patients in the CKD Group were significantly older than those in the Control Group. However, this difference was adjusted in a Cox proportional hazard model, which did not identify age as an independent predictor for sustained ventricular arrhythmia. Not surprisingly, patients in the CKD Group had a higher proportion of ischaemic cardiomyopathy than the Control Group and CKD is well known to be associated with increased risk of atherosclerotic disease, independent of other traditional risk factors. ${ }^{54}$ In the multivariate Cox proportional hazards 
model, this aetiology was not an independent predictor of sustained arrhythmia thereby highlighting that, apart from accelerated CAD, other pathophysiological processes have a role in risk for ventricular arrhythmia. ${ }^{21 ; 25}$ In addition, as with all retrospective analyses of patients with cardiac rhythm devices, there are differences in device programming between patients. Although most patients were programmed with similar primary prevention device settings for detection of treatment of ventricular arrhythmias, $12 \%$ of patients who had not exeperienced therapies since implant were reprogrammed with long detection criteria from the year 2013 onwards in light of the results of the MADIT-RIT trial..$^{55}$ Therefore, the incidence of treated ventricular arrhythmias is likely to have decreased from the latter part of 2013 onwards, although this reflects real-world practice and both groups would likely have been similarly affected. 
Figure 1. Consort diagram showing the study population

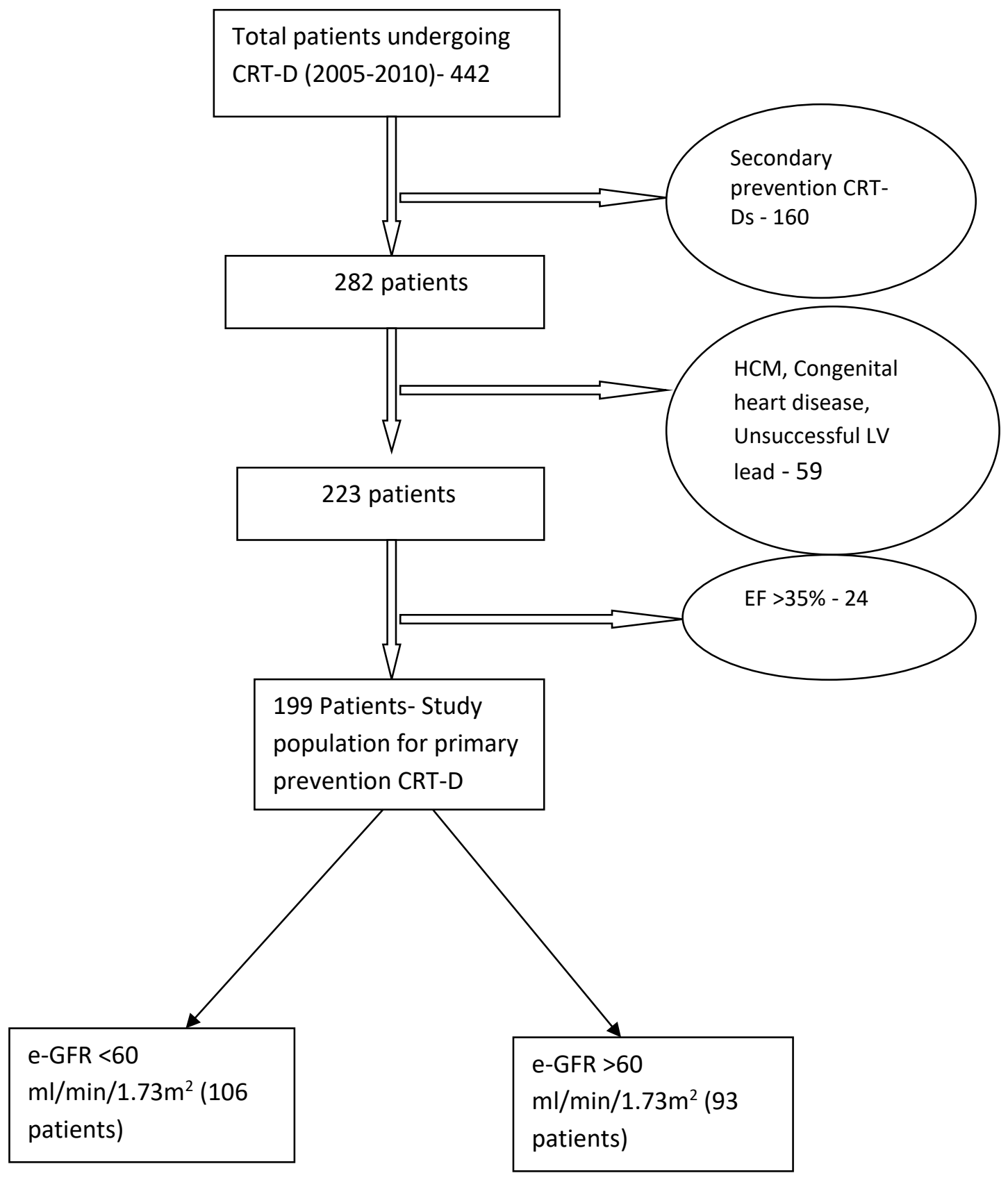

Legend: HCM- Hypertrophic Cardiomyopathy

LV lead- Left ventricular lead 
Table 1 - Comparison of baseline characteristics

\begin{tabular}{|c|c|c|c|}
\hline & $\begin{array}{l}\text { Group } 1(\text { eGFR <60) } \\
n=106\end{array}$ & $\begin{array}{c}\text { Group2 (eGFR } \geq 60 \mathrm{ml} / \mathrm{min} \text { ) } \\
n=93\end{array}$ & $\mathbf{P}$ \\
\hline Mean Age & 70.06 & 62 & $<.05$ \\
\hline Male & $75 \%$ & $70 \%$ & NS \\
\hline $\begin{array}{l}\text { NYHA median } \\
\text { mean }\end{array}$ & $\begin{array}{c}3 \\
2.67\end{array}$ & $\begin{array}{c}3 \\
2.46\end{array}$ & NS \\
\hline Mean LVEF & $24.8 \%$ & $25.0 \%$ & NS \\
\hline Mean QRS width (ms) & 141 & 146 & NS \\
\hline AF prevalence & $36.7 \%$ & $18.3 \%$ & $<.05$ \\
\hline $\begin{array}{l}\text { Ischemic } \\
\text { cardiomyopathy }\end{array}$ & $56.2 \%$ & $40.2 \%$ & $<.05$ \\
\hline Amiodarone & $13.3 \%$ & 7.8 & NS \\
\hline Beta Blocker & $77 \%$ & $81 \%$ & NS \\
\hline ACE inhibitor & $91 \%$ & $94 \%$ & NS \\
\hline
\end{tabular}

Legend:

eGFR - estimated glomerular filtration rate ( $\mathrm{ml} / \mathrm{min})$;

NYHA - New York Heart Association functional class;

LVEF - left ventricular ejection fraction;

ACE - angiotensin converting enzyme 
Figure 2. Interval censored Incidence of sustained VT/VF at $\mathbf{5}$ yrs after device implantation

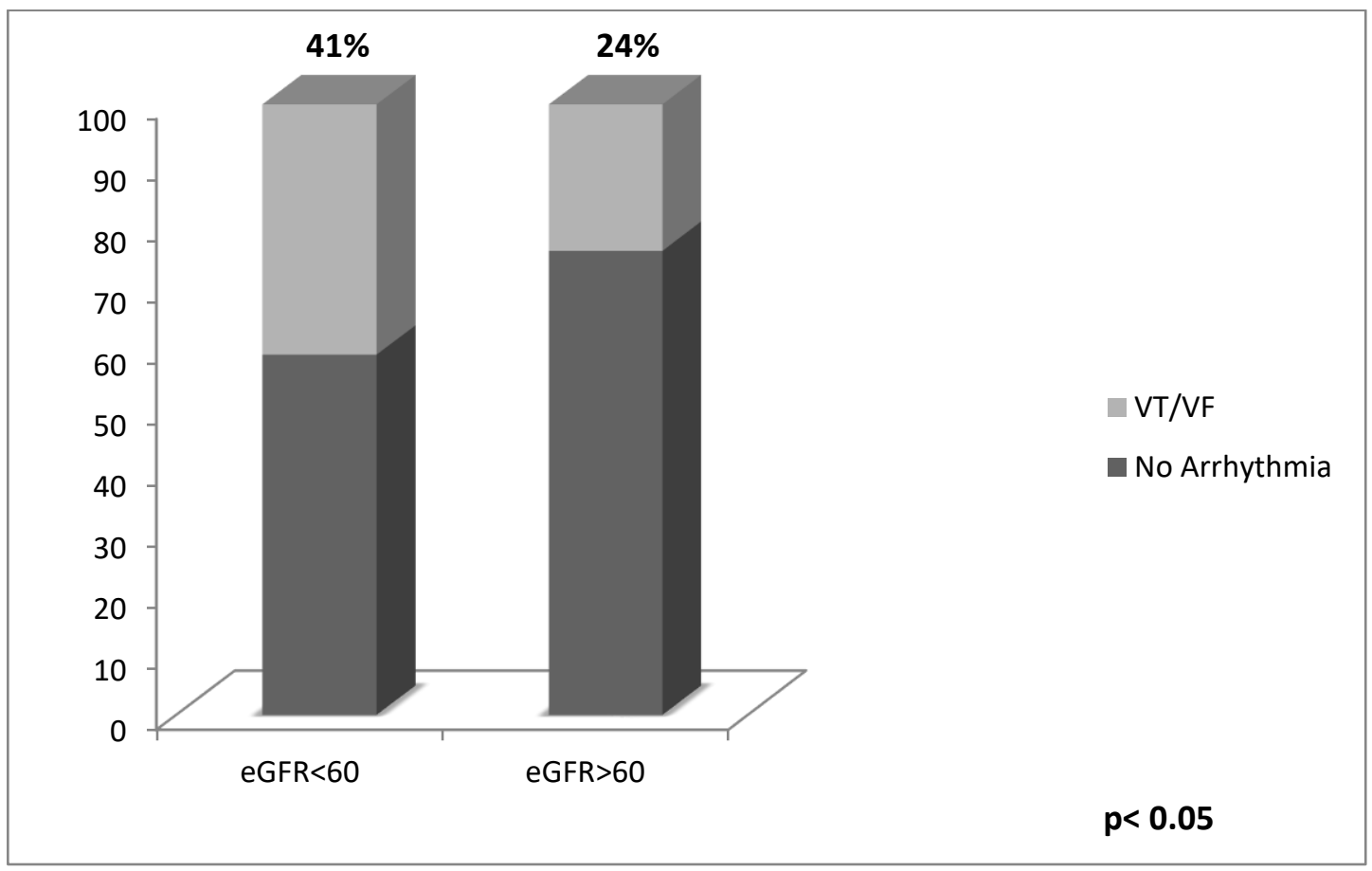

Legend: VT - ventricular tachycardia; VF - ventricular fibrillation. eGFR - estimated glomerular filtration rate $(\mathrm{ml} / \mathrm{min})$. 
Figure 3. Kaplan-Meier curve: Freedom from Sustained VT/VF

\section{Kaplan Meier survival analysis- First VTIF event}

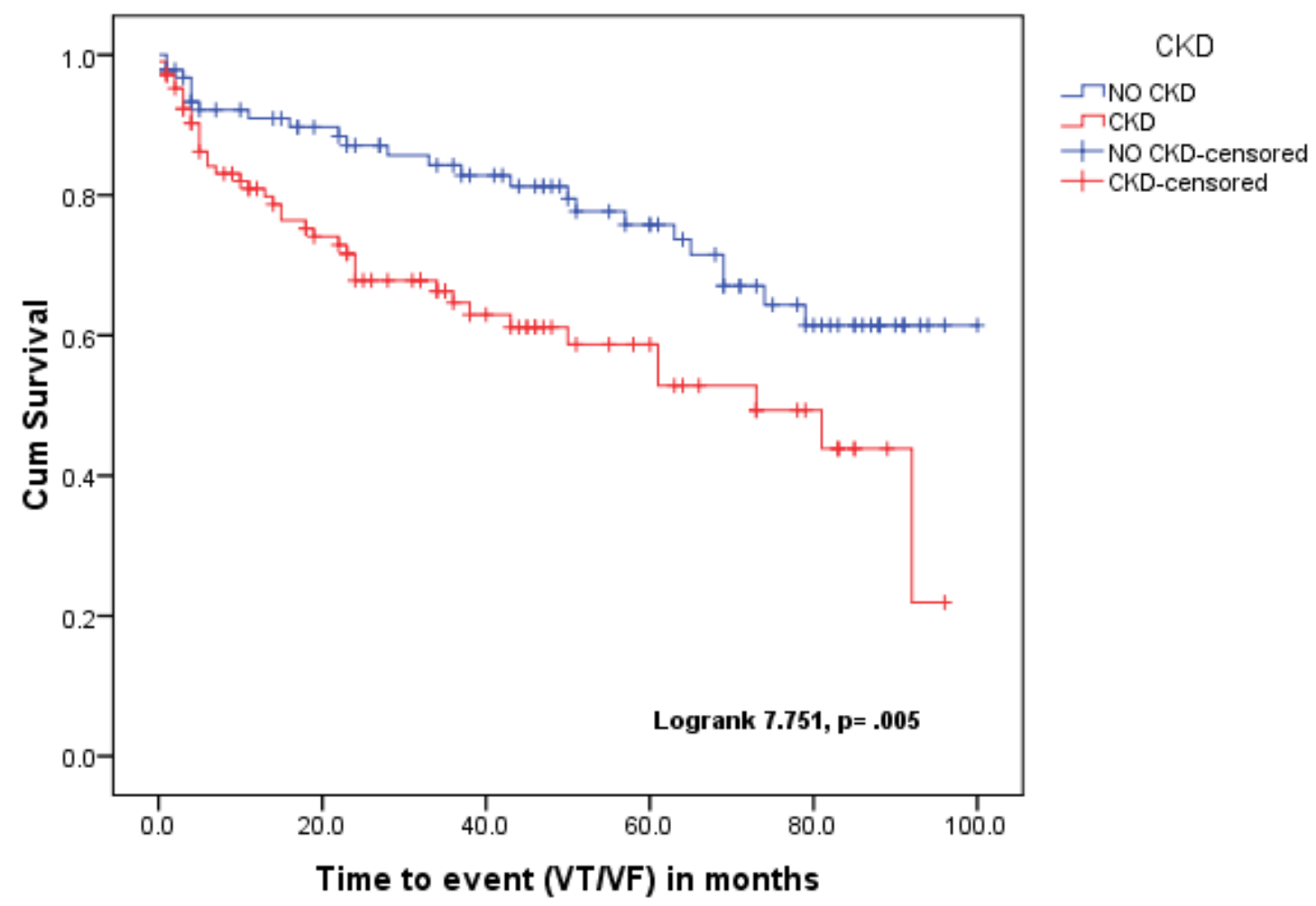

Legend: VT - ventricular tachycardia; VF - ventricular fibrillation; CKD - chronic kidney disease. 
Table 2. Univariate and multivariate cox regression model of VT/VF occurence.

\begin{tabular}{|c|c|c|c|c|c|c|c|c|}
\hline \multicolumn{5}{|c|}{$\begin{array}{l}\text { Univariate analysis } \\
\qquad 95 \% \mathrm{Cl}\end{array}$} & \multicolumn{4}{|c|}{$\begin{array}{r}\text { Multivariate analysis } \\
995 \% \mathrm{Cl}\end{array}$} \\
\hline Variable & HR & LL & UL & $p$ & HR & LL & UL & $\mathbf{P}$ \\
\hline Sex & 1.901 & 1.029 & 3.514 & .040 & - & - & - & NS \\
\hline CKD & 2.034 & 1.219 & 3.394 & .007 & 2.924 & 1.399 & 6.109 & .004 \\
\hline Amiodarone & - & - & - & NS & - & - & - & NS \\
\hline $\begin{array}{l}\text { Beta } \\
\text { blocker }\end{array}$ & - & - & - & NS & - & - & - & NS \\
\hline $\begin{array}{l}\text { ACE } \\
\text { inhibitor }\end{array}$ & - & - & - & NS & - & - & - & NS \\
\hline Age & - & - & - & NS & - & - & - & NS \\
\hline Mean LV EF & 0.966 & 0.933 & 1.0 & .051 & - & - & - & NS \\
\hline NYHA & - & - & - & NS & - & - & - & NS \\
\hline Etiology & 1.673 & 1.011 & 2.768 & 0.045 & - & - & - & NS \\
\hline
\end{tabular}

Legend: $\mathrm{Cl}$ - confidence interval; $\mathrm{HR}$ - hazard ratio; LL - lower limit; UL - upper limit; CKD - chronic kidney disease; ACE - angiotensin converting enzyme; LVEF - left ventricular ejection fraction; NYHA - New York Heart Association functional class. 
Figure 4. Kaplan Meier Curve- All cause mortality

Kaplan Meier Survival analysis- All cause mortality

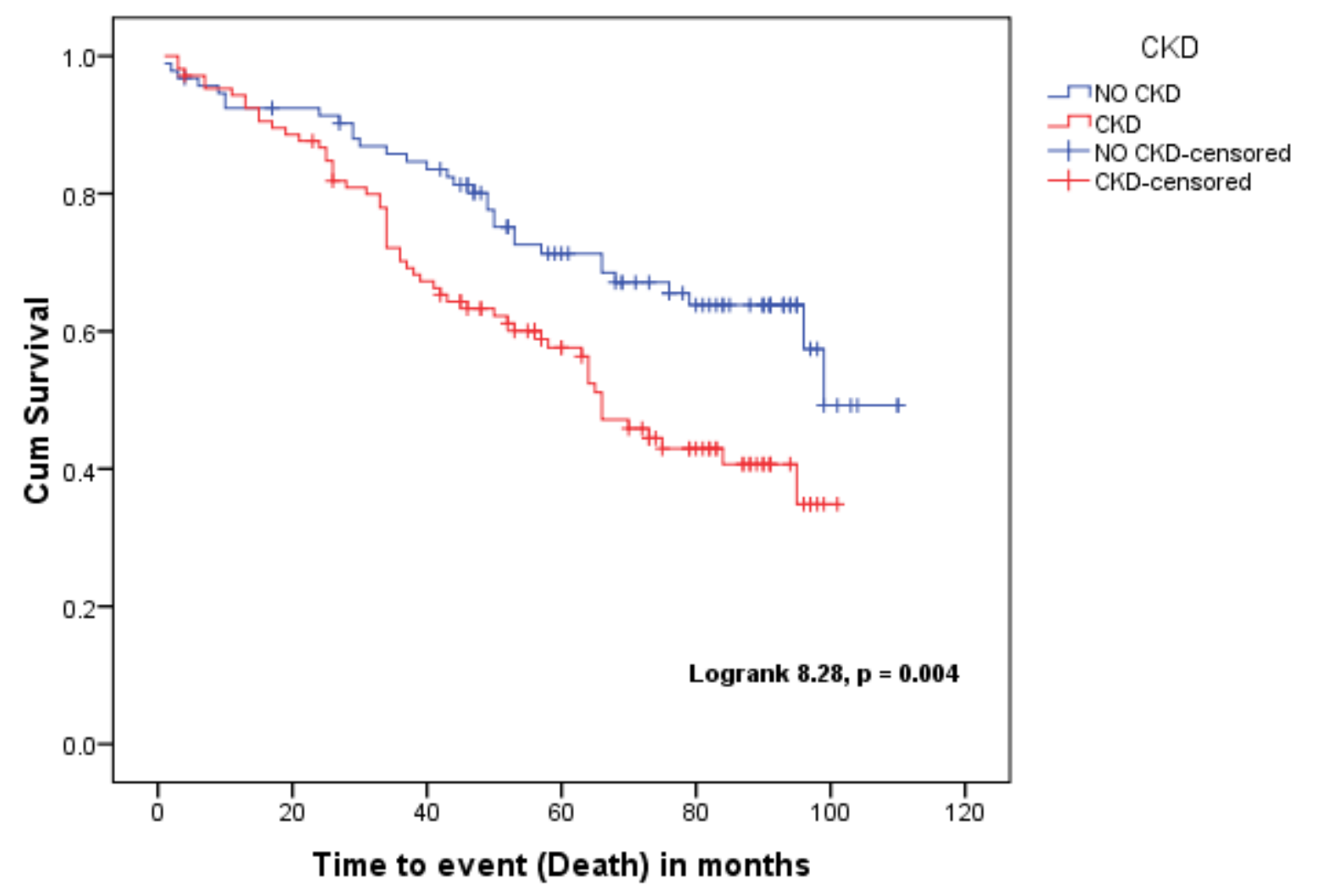

Legend: $\quad$ CKD $\quad-\quad$ chronic $\quad$ kidney disease. 
Table 3 Univariate and multivariate cox regression model of Mortality.

\begin{tabular}{|c|c|c|c|c|c|c|c|c|}
\hline \multicolumn{5}{|c|}{$\begin{array}{r}\text { Univariate analysis } \\
95 \% \mathrm{Cl}\end{array}$} & \multicolumn{4}{|c|}{$\begin{array}{r}\text { Multivariate analysis } \\
95 \% \mathrm{Cl}\end{array}$} \\
\hline Variable & HR & LL & UL & $p$ & HR & LL & UL & $\mathbf{p}$ \\
\hline Sex & 1.980 & 1.128 & 3.475 & .017 & 1.905 & 0.907 & 4.001 & .08 \\
\hline CKD & 1.663 & 1.064 & 2.598 & .026 & - & - & - & NS \\
\hline Amiodarone & - & - & - & NS & - & - & - & NS \\
\hline $\begin{array}{l}\text { Beta } \\
\text { blocker }\end{array}$ & - & - & - & NS & - & - & - & NS \\
\hline $\begin{array}{l}\text { ACE } \\
\text { inhibitor }\end{array}$ & - & - & - & NS & - & - & - & NS \\
\hline Age & 1.032 & 1.011 & 1.053 & .003 & - & - & - & NS \\
\hline Mean LVEF & - & - & - & NS & - & - & - & NS \\
\hline NYHA & 1.579 & 1.110 & 2.246 & 0.011 & - & - & - & NS \\
\hline Etiology & - & - & - & NS & - & - & - & NS \\
\hline
\end{tabular}

Legend: $\mathrm{Cl}$ - confidence interval; HR - hazard ratio; LL - lower limit; UL - upper limit; CKD - chronic kidney dsease; ACE - angiotensin converting enzyme; LVEF - left ventricular ejection fraction; NYHA - New York Heart Association functional class. 
Reference List

1. Cleland JG, Daubert JC, Erdmann E, Freemantle N, Gras D, Kappenberger L, Tavazzi L. The effect of cardiac resynchronization on morbidity and mortality in heart failure. $N$ Engl J Med. 2005;352:1539-1549.

2. Bardy GH, Lee KL, Mark DB, Poole JE, Packer DL, Boineau R, Domanski M, Troutman C, Anderson J, Johnson G, McNulty SE, Clapp-Channing N, Davidson-Ray LD, Fraulo ES, Fishbein $\mathrm{DP}$, Luceri RM, Ip JH. Amiodarone or an implantable cardioverter-defibrillator for congestive heart failure. N Engl J Med. 2005;352:225-237.

3. Bristow MR, Saxon LA, Boehmer J, Krueger S, Kass DA, De Marco T, Carson P, DiCarlo L, DeMets D, White BG, DeVries DW, Feldman AM. Cardiac-resynchronization therapy with or without an implantable defibrillator in advanced chronic heart failure. $N$ Engl J Med. 2004;350:2140-2150.

4. Ezzat VA, Lee V, Ahsan S, Chow AW, Segal O, Rowland E, Lowe MD, Lambiase PD. A systematic review of ICD complications in randomised controlled trials versus registries: is our 'real-world' data an underestimation? Open Heart. 2015;2:e000198.

5. Goldenberg I, Vyas AK, Hall WJ, Moss AJ, Wang H, He H, Zareba W, McNitt S, Andrews ML. Risk stratification for primary implantation of a cardioverter-defibrillator in patients with ischemic left ventricular dysfunction. J Am Coll Cardiol. 2008;51:288-296.

6. Moss AJ, Fadl Y, Zareba W, Cannom DS, Hall WJ. Survival benefit with an implanted defibrillator in relation to mortality risk in chronic coronary heart disease. Am J Cardiol. 2001;88:516-520.

7. Sheldon R, Connolly S, Krahn A, Roberts R, Gent M, Gardner M. Identification of patients most likely to benefit from implantable cardioverter-defibrillator therapy: the Canadian Implantable Defibrillator Study. Circulation. 2000;101:1660-1664.

8. Go AS, Yang J, Ackerson LM, Lepper K, Robbins S, Massie BM, Shlipak MG. Hemoglobin level, chronic kidney disease, and the risks of death and hospitalization in adults with chronic heart failure: the Anemia in Chronic Heart Failure: Outcomes and Resource Utilization (ANCHOR) Study. Circulation. 2006;113:2713-2723.

9. Walsh CR, O'Donnell CJ, Camargo CA, Jr., Giugliano RP, Lloyd-Jones DM. Elevated serum creatinine is associated with 1-year mortality after acute myocardial infarction. Am Heart J. 2002;144:1003-1011.

10. Manjunath G, Tighiouart H, Coresh J, Macleod B, Salem DN, Griffith JL, Levey AS, Sarnak MJ. Level of kidney function as a risk factor for cardiovascular outcomes in the elderly. Kidney Int. 2003;63:1121-1129.

11. Hillege HL, Nitsch D, Pfeffer MA, Swedberg K, McMurray JJ, Yusuf S, Granger CB, Michelson EL, Ostergren J, Cornel JH, de Zeeuw D, Pocock S, van Veldhuisen DJ. Renal function as a predictor of outcome in a broad spectrum of patients with heart failure. Circulation. 2006;113:671-678. 
12. Anavekar NS, McMurray JJ, Velazquez EJ, Solomon SD, Kober L, Rouleau JL, White HD, Nordlander R, Maggioni A, Dickstein K, Zelenkofske S, Leimberger JD, Califf RM, Pfeffer MA. Relation between renal dysfunction and cardiovascular outcomes after myocardial infarction. N Engl J Med. 2004;351:1285-1295.

13. Smith GL, Lichtman JH, Bracken MB, Shlipak MG, Phillips CO, DiCapua P, Krumholz HM. Renal impairment and outcomes in heart failure: systematic review and meta-analysis. J Am Coll Cardiol. 2006;47:1987-1996.

14. Mathew J, Katz R, St John SM, Dixit S, Gerstenfeld EP, Ghio S, Gold MR, Linde C, Shlipak MG, Deo R. Chronic kidney disease and cardiac remodelling in patients with mild heart failure: results from the REsynchronization reVErses Remodeling in Systolic Left vEntricular Dysfunction (REVERSE) study. Eur J Heart Fail. 2012;14:1420-1428.

15. National Kidney Foundation. K/DOQI clinical practice guidelines for chronic kidney disease: evaluation, classification, and stratification. S1-266. 1-2-2002. American Journal of Kidney Diseases.

Ref Type: Report

16. Deo R, Sotoodehnia N, Katz R, Sarnak MJ, Fried LF, Chonchol M, Kestenbaum B, Psaty BM, Siscovick DS, Shlipak MG. Cystatin C and sudden cardiac death risk in the elderly. Circ Cardiovasc Qual Outcomes. 2010;3:159-164.

17. Tonelli M, Wiebe N, Culleton B, House A, Rabbat C, Fok M, McAlister F, Garg AX. Chronic kidney disease and mortality risk: a systematic review. J Am Soc Nephrol. 2006;17:20342047.

18. Drey N, Roderick $\mathrm{P}$, Mullee $\mathrm{M}$, Rogerson M. A population-based study of the incidence and outcomes of diagnosed chronic kidney disease. Am J Kidney Dis. 2003;42:677-684.

19. Keith DS, Nichols GA, Gullion CM, Brown JB, Smith DH. Longitudinal follow-up and outcomes among a population with chronic kidney disease in a large managed care organization. Arch Intern Med. 2004;164:659-663.

20. Parfrey PS, Foley RN. The clinical epidemiology of cardiac disease in chronic renal failure. $J$ Am Soc Nephrol. 1999;10:1606-1615.

21. Deo R, Fyr CL, Fried LF, Newman AB, Harris TB, Angleman S, Green C, Kritchevsky SB, Chertow GM, Cummings SR, Shlipak MG. Kidney dysfunction and fatal cardiovascular disease--an association independent of atherosclerotic events: results from the Health, Aging, and Body Composition (Health ABC) study. Am Heart J. 2008;155:62-68.

22. Kreuz J, Balta O, Linhart M, Fimmers R, Lickfett L, Mellert F, Nickenig G, Schwab JO. An impaired renal function and advanced heart failure represent independent predictors of the incidence of malignant ventricular arrhythmias in patients with an implantable cardioverter/defibrillator for primary prevention. Europace. 2010;12:1439-1445.

23. Adams KF, Jr., Patterson JH, Oren RM, Mehra MR, O'Connor CM, Pina IL, Miller AB, Chiong JR, Dunlap SH, Cotts WG, Felker GM, Schocken DD, Schwartz TA, Ghali JK. Prospective assessment of the occurrence of anemia in patients with heart failure: results from the Study of Anemia in a Heart Failure Population (STAMINA-HFP) Registry. Am Heart J. 2009;157:926932. 
24. Cannizzaro LA, Piccini JP, Patel UD, Hernandez AF. Device therapy in heart failure patients with chronic kidney disease. J Am Coll Cardiol. 2011;58:889-896.

25. Whitman IR, Feldman HI, Deo R. CKD and sudden cardiac death: epidemiology, mechanisms, and therapeutic approaches. J Am Soc Nephrol. 2012;23:1929-1939.

26. Moss AJ, Zareba W, Hall WJ, Klein H, Wilber DJ, Cannom DS, Daubert JP, Higgins SL, Brown MW, Andrews ML. Prophylactic implantation of a defibrillator in patients with myocardial infarction and reduced ejection fraction. N Engl J Med. 2002;346:877-883.

27. Goldenberg I, Moss AJ, McNitt S, Zareba W, Andrews ML, Hall WJ, Greenberg H, Case RB. Relations among renal function, risk of sudden cardiac death, and benefit of the implanted cardiac defibrillator in patients with ischemic left ventricular dysfunction. Am J Cardiol. 2006;98:485-490.

28. Goldenberg I, Moss AJ. Implantable cardioverter defibrillator efficacy and chronic kidney disease: competing risks of arrhythmic and nonarrhythmic mortality. J Cardiovasc Electrophysiol. 2008;19:1281-1283.

29. Amin MS, Fox AD, Kalahasty G, Shepard RK, Wood MA, Ellenbogen KA. Benefit of primary prevention implantable cardioverter-defibrillators in the setting of chronic kidney disease: a decision model analysis. J Cardiovasc Electrophysiol. 2008;19:1275-1280.

30. Richardson M, Freemantle N, Calvert MJ, Cleland JG, Tavazzi L. Predictors and treatment response with cardiac resynchronization therapy in patients with heart failure characterized by dyssynchrony: a pre-defined analysis from the CARE-HF trial. Eur Heart J. 2007;28:18271834.

31. Tang AS, Wells GA, Talajic M, Arnold MO, Sheldon R, Connolly S, Hohnloser SH, Nichol G, Birnie DH, Sapp JL, Yee R, Healey JS, Rouleau JL. Cardiac-resynchronization therapy for mildto-moderate heart failure. N Engl J Med. 2010;363:2385-2395.

32. Linde C, Abraham WT, Gold MR, St John SM, Ghio S, Daubert C. Randomized trial of cardiac resynchronization in mildly symptomatic heart failure patients and in asymptomatic patients with left ventricular dysfunction and previous heart failure symptoms. J Am Coll Cardiol. 2008;52:1834-1843.

33. Saxon LA, Bristow MR, Boehmer J, Krueger S, Kass DA, De Marco T, Carson P, DiCarlo L, Feldman AM, Galle E, Ecklund F. Predictors of sudden cardiac death and appropriate shock in the Comparison of Medical Therapy, Pacing, and Defibrillation in Heart Failure (COMPANION) Trial. Circulation. 2006;114:2766-2772.

34. Cerasola G, Nardi E, Mule G, Palermo A, Cusimano P, Guarneri M, Arsena R, Giammarresi G, Carola FA, Cottone $S$. Left ventricular mass in hypertensive patients with mild-to-moderate reduction of renal function. Nephrology (Carlton ). 2010;15:203-210.

35. Levin A, Thompson CR, Ethier J, Carlisle EJ, Tobe S, Mendelssohn D, Burgess E, Jindal K, Barrett B, Singer J, Djurdjev O. Left ventricular mass index increase in early renal disease: impact of decline in hemoglobin. Am J Kidney Dis. 1999;34:125-134.

36. Moran A, Katz R, Jenny NS, Astor B, Bluemke DA, Lima JA, Siscovick D, Bertoni AG, Shlipak MG. Left ventricular hypertrophy in mild and moderate reduction in kidney function 
determined using cardiac magnetic resonance imaging and cystatin C: the multi-ethnic study of atherosclerosis (MESA). Am J Kidney Dis. 2008;52:839-848.

37. Paoletti E, Bellino D, Cassottana P, Rolla D, Cannella G. Left ventricular hypertrophy in nondiabetic predialysis CKD. Am J Kidney Dis. 2005;46:320-327.

38. Haider AW, Larson MG, Benjamin EJ, Levy D. Increased left ventricular mass and hypertrophy are associated with increased risk for sudden death. J Am Coll Cardiol. 1998;32:1454-1459.

39. Cioffi G, Tarantini L, Frizzi R, Stefenelli C, Russo TE, Selmi A, Toller C, Furlanello F, de Simone G. Chronic kidney disease elicits excessive increase in left ventricular mass growth in patients at increased risk for cardiovascular events. J Hypertens. 2011;29:565-573.

40. Hunter JJ, Chien KR. Signaling pathways for cardiac hypertrophy and failure. N Engl J Med. 1999;341:1276-1283.

41. Amann K, Kronenberg G, Gehlen F, Wessels S, Orth S, Munter K, Ehmke H, Mall G, Ritz E. Cardiac remodelling in experimental renal failure--an immunohistochemical study. Nephrol Dial Transplant. 1998;13:1958-1966.

42. Mall G, Huther W, Schneider J, Lundin P, Ritz E. Diffuse intermyocardiocytic fibrosis in uraemic patients. Nephrol Dial Transplant. 1990;5:39-44.

43. Reinier K, Dervan C, Singh T, Uy-Evanado A, Lai S, Gunson K, Jui J, Chugh SS. Increased left ventricular mass and decreased left ventricular systolic function have independent pathways to ventricular arrhythmogenesis in coronary artery disease. Heart Rhythm. 2011;8:11771182.

44. Yan AT, Shayne AJ, Brown KA, Gupta SN, Chan CW, Luu TM, Di Carli MF, Reynolds HG, Stevenson WG, Kwong RY. Characterization of the peri-infarct zone by contrast-enhanced cardiac magnetic resonance imaging is a powerful predictor of post-myocardial infarction mortality. Circulation. 2006;114:32-39.

45. Roes SD, Borleffs CJ, van der Geest RJ, Westenberg JJ, Marsan NA, Kaandorp TA, Reiber JH, Zeppenfeld K, Lamb HJ, de Roos A, Schalij MJ, Bax JJ. Infarct tissue heterogeneity assessed with contrast-enhanced MRI predicts spontaneous ventricular arrhythmia in patients with ischemic cardiomyopathy and implantable cardioverter-defibrillator. Circ Cardiovasc Imaging. 2009;2:183-190.

46. Schmidt A, Azevedo CF, Cheng A, Gupta SN, Bluemke DA, Foo TK, Gerstenblith G, Weiss RG, Marban E, Tomaselli GF, Lima JA, Wu KC. Infarct tissue heterogeneity by magnetic resonance imaging identifies enhanced cardiac arrhythmia susceptibility in patients with left ventricular dysfunction. Circulation. 2007;115:2006-2014.

47. Morita N, Sovari AA, Xie Y, Fishbein MC, Mandel WJ, Garfinkel A, Lin SF, Chen PS, Xie LH, Chen F, Qu Z, Weiss JN, Karagueuzian HS. Increased susceptibility of aged hearts to ventricular fibrillation during oxidative stress. Am J Physiol Heart Circ Physiol. 2009;297:H1594-H1605.

48. Wolk R. Arrhythmogenic mechanisms in left ventricular hypertrophy. Europace. 2000;2:216223. 
49. Koomans HA, Blankestijn PJ, Joles JA. Sympathetic hyperactivity in chronic renal failure: a wake-up call. J Am Soc Nephrol. 2004;15:524-537.

50. Neumann J, Ligtenberg G, Klein II, Koomans HA, Blankestijn PJ. Sympathetic hyperactivity in chronic kidney disease: pathogenesis, clinical relevance, and treatment. Kidney Int. 2004;65:1568-1576.

51. Leineweber K, Heinroth-Hoffmann I, Ponicke K, Abraham G, Osten B, Brodde OE. Cardiac beta-adrenoceptor desensitization due to increased beta-adrenoceptor kinase activity in chronic uremia. J Am Soc Nephrol. 2002;13:117-124.

52. Zoccali C, Mallamaci F, Parlongo S, Cutrupi S, Benedetto FA, Tripepi G, Bonanno G, Rapisarda F, Fatuzzo P, Seminara G, Cataliotti A, Stancanelli B, Malatino LS. Plasma norepinephrine predicts survival and incident cardiovascular events in patients with end-stage renal disease. Circulation. 2002;105:1354-1359.

53. Morris ST, Galiatsou E, Stewart GA, Rodger RS, Jardine AG. QT dispersion before and after hemodialysis. J Am Soc Nephrol. 1999;10:160-163.

54. Baber U, Gutierrez OM, Levitan EB, Warnock DG, Farkouh ME, Tonelli M, Safford MM, Muntner P. Risk for recurrent coronary heart disease and all-cause mortality among individuals with chronic kidney disease compared with diabetes mellitus, metabolic syndrome, and cigarette smokers. Am Heart J. 2013;166:373-380.

55. Moss AJ, Schuger C, Beck CA, Brown MW, Cannom DS, Daubert JP, Estes NA, III, Greenberg H, Hall WJ, Huang DT, Kautzner J, Klein H, McNitt S, Olshansky B, Shoda M, Wilber D, Zareba W. Reduction in inappropriate therapy and mortality through ICD programming. $N$ Engl J Med. 2012;367:2275-2283. 